\title{
Existem espíritos livres entre nós?
}

\author{
Olímpio Pimenta*
}

\begin{abstract}
Resumo: Considerando declarações feitas por Nietzsche nas distintas fases de sua obra, pretendemos discutir se nossas práticas atuais de ensino e pesquisa, marcadas pelo zelo erudito e pela especialização, contribuem ou não para a formação de espíritos livres, não sem antes vincular esta noção ao curso geral de uma filosofia comprometida com a afirmação da existência.

Palavras-chave: erudição - especialização - espíritos livres - afirmação da existência
\end{abstract}

O ponto de partida desta breve reflexão é a constatação de uma estratégia hegemônica para o estudo de Nietzsche entre nós atualmente, centrada na consolidação do marco erudito. A título de especulação, ficamos tentados a conjecturar se isso seria consequência do estabelecimento editorial das obras completas, consistindo em etapa do processo de aquisição de respeitabilidade acadêmica pelo autor. Se tem cabimento falar, por essa via, em canonização, não deixa de ser irônico lembrar que, ao prever semelhante desdobramento para a recepção de seus pensamentos, "prestes, receio, a se tornarem verdades: tão imortal já é seu aspecto, tão pateticamente honrado, tão enfadonho!", Nietzsche evoque a manhã deles, hora em que ainda eram, inequivocamente, "maus pensamentos" (JGB/ BM 296, KSA 5.296).

* Professor do Departamento de Filosofia da Universidade Federal de Ouro Preto (DEFIL/ IFAC/UFOP), Ouro Preto, MG, Brasil. E-mail: olimpix@ig.com.br. 
Pimenta, O.

Pode-se indicar, como característicos, os seguintes traços desta orientação geral de leitura e ensino: a prioridade dada à pesquisa de fontes, convergindo para a restituição da procedência das ideias de Nietzsche; a contextualização exaustiva de tais ideias em relação aos debates públicos em andamento no século dezenove; a inscrição do pensamento de Nietzsche no curso dos debates que constituem a história da filosofia propriamente dita; a tendência ao questionamento da integridade do percurso intelectual do filósofo, tensionado pela heterogeneidade dos aportes teóricos acolhidos ao longo da evolução de suas posições filosóficas.

Sobre este último traço, dado seu relevo filosófico diferenciado, convém uma investigação preliminar à parte, sem perder de vista a indissociabilidade entre pensamento e vida e o trânsito contínuo entre os dois âmbitos, reivindicados, por exemplo, quando Nietzsche diz que:

Todos eles [os filósofos] agem como se tivessem descoberto ou alcançado suas opiniões próprias pelo desenvolvimento autônomo de uma dialética fria, pura, divinamente imperturbável (à diferença dos místicos de toda espécie, que são mais honestos e toscos - falam de "inspiração"): quando no fundo é uma tese adotada de antemão, uma idéia inesperada, uma "intuição", em geral um desejo íntimo tornado abstrato e submetido a um crivo, que eles defendem com razões que buscam posteriormente (JGB/ BM 5, KSA 5.18-9).

\section{Ou ainda:}

Gradualmente foi se revelando para mim o que toda grande filosofia foi até o momento: a confissão pessoal de seu autor, uma espécie de memórias involuntárias e inadvertidas; e também se tornou claro que as intenções morais (ou imorais) de toda filosofia constituíram sempre o germe a partir do qual cresceu a planta inteira (JGB/BM 6, KSA 5.19-21).

166 I Cad. Nietzsche, São Paulo, n. 33, p. 165-180, 2013. 
A admissão dessa espécie de premissa, válida inclusive para o filosofar de Nietzsche, explicaria algumas mudanças de ênfase e vocabulário e a aquisição de repertório categorial próprio em função de mudanças profissionais e biográficas. Por conseguinte, seria admissível considerar que conflitos textuais refletissem conflitos existenciais, provando coerência onde parecia haver contradição. Em todo caso, fica assim a questão: será possível integrar as variações verificadas na enunciação e no conteúdo dos escritos de Nietzsche em um plano coerente? Dito de outra maneira: a periodização tradicional prova a vigência de rupturas irreconciliáveis ou sinaliza a favor de algum tipo de continuidade?

Nossa opção é explorar a segunda vertente da alternativa, relativizando a importância das reviravoltas em função de uma perspectiva programática geral, testemunha de um percurso altamente coerente. Para tanto, tomaremos a afirmação da existência como fio de Ariadne para a movimentação no interior da obra. $\mathrm{O}$ desenvolvimento da hipótese pode ser levado a efeito através de três instâncias, correspondentes às três etapas da periodização referida.

No primeiro momento, o leitor se encontra na companhia de um Nietzsche entusiasta da tragédia. Importava então para o pensador o entendimento de como a cultura grega celebrou a vida, não obstante o reconhecimento de seus temores e horrores, mas também o aprendizado, junto a ela, da sabedoria dionisíaca, talvez capaz de promover um renascimento moderno da tragédia. Porque a narrativa conceitual que constitui o livro de estréia é muito conhecida, indicaremos de forma sumária seus aspectos centrais. A tese principal vincula o desenvolvimento da arte trágica à dualidade entre os impulsos antagônicos da individuação e da indiferenciação, representados pela cultura grega com o par Apolo e Dioniso. A criação de tais divindades, por sua vez, seria indício de uma sabedoria radical acerca da condição do homem no mundo, capaz de ver nos movimentos de configuração e dissolução aquilo que é essencial nos processos da existência, e cujo reconhecimento pode ser jubiloso. 
Pimenta, O.

Como se sabe, ocorre depois uma recusa, por parte do filósofo, dessa sua primeira formulação cosmológica. Os comprometimentos teóricos dessa metafísica de artistas com, justamente, um pensamento ainda demasiado metafísico, são rejeitados sem apelação por ele. Donde o primeiro questionamento: deve-se aceitar a proposta ou sua autocrítica, isto é, deve-se admitir o que é defendido no livro ou deve-se contestar sua validade? E, mais grave: se o autor concede que não tinha razão de início, como saber se ele segue ou não sem razão depois? Seria como num tribunal: se uma testemunha admite ter mentido, sua credibilidade fica contaminada inclusive em relação a essa admissão.

Segundo nossa hipótese, temos aqui, muito diversamente, um primeiro efeito explicável pelo recurso ao programa geral da afirmação da existência. Embora enredada em uma estranha trama metafísica, refém do dualismo que irá ser repudiado adiante como um dos principais defeitos hereditários dos filósofos, o lance executado ali se alimenta de uma saúde fundamental. Isto porque, mesmo que implicada com encaminhamentos devedores de esquemas mentais alheios, a tarefa propriamente nietzschiana já se impôs com clareza:

Contra a moral, portanto, voltou-se então, com esse livro problemático, o meu instinto, como um instinto em prol da vida, e inventou para si, fundamentalmente, uma contradoutrina e uma contravaloração da vida, puramente artística, anticristã. Como denominá-la? Na qualidade de filólogo e homem das palavras eu a batizei, não sem alguma liberdade - pois quem conheceria verdadeiramente o nome do Anticristo? - com o nome de um deus grego: eu a chamei dionisíaca (GT/NT, Ensaio de autocrítica, 5, KSA 1.17-9).

Os escritos que se seguem trazem uma mudança significativa quanto aos assuntos em discussão. É ostensivo o elogio da afinidade com as coisas próximas, no interior de um quadro conceitual deflacionado por aportes céticos e materialistas. Um Nietzsche amigo dos espíritos livres preconiza a revalorização da

168 I Cad. Nietzsche, São Paulo, n. 33, p. 165-180, 2013. 
racionalidade e do conhecimento científico. Destaca-se em seu filosofar a atenção às dimensões psicológica e fisiológica da experiência individual e cultural, e com ela amadurecem o procedimento genealógico e o perspectivismo.

Aos olhos do leitor treinado na escola da especialização erudita, temos nisso um problema. Qual a convergência possível entre o caloroso apologista do drama musical wagneriano e o sóbrio adepto do materialismo de Lange, cujo cultivo prospera à luz das lições de método? Para um leitor assim, a incompatibilidade entre a "doutrina misteriosófica da tragédia" (GT/NT 10, KSA 1.71-5) e a "filosofia histórica, que não se pode mais conceber como distinta da ciência natural" (MA I/HH I 1, KSA 2.23-4) força a escolha: ou acolhemos a primeira, e com isso desistimos de nossa retidão intelectual, ou acolhemos o segundo, e com isso desistimos dos transportes jubilosos da alegria dionisíaca.

Novamente nossa hipótese pode ser útil. Talvez valha considerar, em ambos os casos, a prevalência dos fins sobre os meios. Nesse sentido, em que pesem as enormes diferenças entre os propósitos e procedimentos que as constituem, a arte trágica e a ciência moderna apareceriam como empreendimentos a serem apreciados em função de seu serviço ou desserviço à afirmação da existência. Com alcance distinto, cada uma delas responderia pela elaboração de uma dimensão específica da experiência, podendo ser mais ou menos ajustadas ao curso de uma educação filosófica superior, voltada para o aprendizado da aprovação irrestrita da vida, não obstante a admissão de sua amoralidade e insignificância intrínsecas.

$\mathrm{Na}$ etapa seguinte, encontra-se um Nietzsche interessado em tornar-se médico da civilização. Suas reflexões resultam na escrita de narrativas globais sobre a emergência e a crise dos valores centrais da cultura ocidental, secundadas pela enunciação dos chamados grandes temas de sua filosofia, matéria para meditação e experimentação individual e coletiva. A contenção dos escritos imediatamente precedentes é substituída por uma prosa vibrante, por vezes polêmica, ocupada com a invenção de metas ecumênicas capazes de 
Pimenta, O.

mobilizar os corações e as mentes de seu público, terreno em que a superação das velhas formas do viver deveria enfim prosperar.

Como se não bastassem as dificuldades anteriores, resta ao intérprete compatibilizar esta nova figura com as duas primeiras. Mais uma vez, o recurso à unidade programática mostra-se oportuno. Uma filosofia dionisíaca não é estranha a qualquer atividade humana, desde que esta se integre a seus objetivos, doravante fixados em torno dos experimentos transvaloração dos valores, amor fati, gaia ciência, ensino do além do homem, e assim por diante. Em suma: tratar-se-ia, com Nietzsche, do princípio ao fim, de buscar a superação de toda sensibilidade mórbida, negadora de nossa condição terrena, em direção à afirmação da existência. A integridade peculiar a um tal projeto filosófico está em sua permanente indiferença em relação a qualquer justificação transcendente para o que se vive, em nome da vida mesma neste mundo, depois da admissão de que é impossível, mas antes de tudo indesejável, acercarmo-nos dela obcecados pela questão da sua falta de sentido.

Se estivermos certos, um sem número de formulações desenvolve as implicações deste pensamento nuclear. A rigor, a filosofia nietzschiana propriamente dita consistiria na articulação entre todos os conteúdos que lemos em seus escritos em relação a tal pensamento, reverberações e repercussões impressionantes de uma atitude filosófica e existencial alimentada, antes de tudo, pela alegria. Seguindo essa trilha, compete explorar a seguir o tema particular anunciado de início, considerando seus nexos com o exposto até aqui. Vale dizer, trata-se então de considerar se e como nossas práticas acadêmicas favorecem ou não o cultivo da liberdade de espírito, tomando esta última como um dos conteúdos aludidos em que se pode verificar a presença ou não da afirmação da existência.

Para determinar os termos da discussão a partir de Nietzsche, iremos considerar uma série de declarações feitas em contextos variados, mas cujo foco comum é a prevalência das diretrizes eruditas na formação filosófica. Três tópicos vão franquear nossa entrada no assunto. Em primeiro lugar, cabe restituir a consideração direta 
sobre os riscos da erudição ligada aos excessos do sentido histórico, aos efeitos da especialização e à questão da hierarquia entre o chamado homem objetivo e outros tipos de homem. Depois, interessa recuperar observações pontuais sobre a relação entre trabalho e contemplação na época moderna, que novamente apontam para determinados riscos a serem evitados. Por fim, trata-se de revisitar algumas noções a propósito da distinção entre instinto de rebanho e indivíduo de exceção, que mostram de maneira suficientemente clara as expectativas de Nietzsche em relação à posição do filósofo que merece ser chamado por este nome no concerto geral do mundo. Quanto aos excessos do sentido histórico, que se confundem na contemporaneidade com os excessos da erudição ela mesma, vem a propósito uma longa citação:

Em que situações desnaturadas, artificiais, e, em todo caso, indignas, há de cair, em uma época que sofre de cultura geral, a mais verdadeira de todas as ciências, a deusa nua e sincera, a filosofia?!? Em um tal mundo da unidade exterior imposta, ela permanece um monólogo erudito do passeante solitário, uma presa casual do indivíduo, um segredo oculto de alcova ou uma tagarelice inofensiva entre velhos acadêmicos e crianças. Ninguém deve ousar cumprir a lei da filosofia em si, ninguém vive filosoficamente, com aquela simples lealdade que obrigava o homem antigo a portar-se como estóico onde quer que estivesse, no que quer que empreendesse, caso tivesse um dia jurado lealdade ao Pórtico. Todo filosofar moderno é político e policialesco, limitado à aparência erudita pelos governos, igrejas, academias, hábitos, e pela pusilanimidade dos homens: ele permanece suspirando 'mas se...' ou reconhecendo 'era uma vez...'. No interior da cultura histórica, caso queira ser algo mais do que um saber interiormente contido e sem efeitos, a filosofia não tem direito algum; fosse o homem moderno corajoso e decidido, ele não seria, mesmo em suas inimizades, somente um ser interior: ele baniria a filosofia; agora, ele se contenta em disfarçar envergonhadamente sua nudez. Sim pensa-se, escreve-se, imprime-se, fala-se, ensina-se filosoficamente-até aí tudo é mais ou menos permitido; somente no agir, na assim chamada vida, é diferente: aí apenas 
Pimenta, O.

uma única coisa é permitida e todo o resto é simplesmente impossível: assim o quer a cultura histórica. Será que ainda são homens - perguntamo-nos então - ou talvez somente máquinas de pensar, de escrever, de falar? (HL/Co. Ext. II 5, KSA 1.279-85).

O fulcro da conversa é evidente: porque não há compromisso entre o que se pensa e o que se vive, é possível para alguém pensar de mil maneiras diferentes, aprendidas na frequentação das inúmeras bibliotecas virtuais ao alcance da mão, enquanto sua situação no mundo permanece definida pelo hábito, pela reação irrefletida ao assédio do meio ou, na maioria dos casos, pelo cálculo pragmático de vantagens, associado à mera subsistência. A lei da filosofia é ignorada, a começar pelos professores de filosofia, que nada querem com ela. Em geral se ouve deles que suas obrigações de ofício são as mesmas que as de qualquer colega de magistério, isto é, lhes basta passar a matéria, aplicar as provas e aferir se as competências a serem ministradas estão sendo assimiladas sem distinção por uma classe de indivíduos despersonalizados. Tanto faz o que se estuda e quem o estuda, pois predomina a completa exterioridade: são assuntos e serem entendidos e recortados de modo a caberem no molde de uma monografia que irá render um título, condição administrativa exigida para assegurar ao iniciante alguma perspectiva de carreira. Nesse cenário desolador, a erudição se despede de qualquer vínculo vital e passa a servir de equipamento para a escalada rumo às bolsas de produtividade e à inserção nos grupos institucionalizados, coroada pela conversão final ao academicismo. $\mathrm{O}$ que mais se lamenta aqui é que algo surgido originalmente como uma força a favor da vida - afinal, na excelência de artesão do erudito de outras épocas imperava o compromisso, de dever e amor, com o que quer que estivesse sob seus cuidados - tenha se tornado adversário da vida filosófica.

Ao lado disso, o desprezo pela formação de uma visão de conjunto acerca de qualquer domínio da cultura impede o distanciamento crítico e confina o saber filosófico a uma compartimentação 
que resulta demasiado pobre para lidar com as questões clássicas do campo. O sucesso das ciências positivas é a influência ambivalente que responde por isso. Se, nelas, a especialização e a divisão do trabalho são vantajosas, na medida em que levam ao acúmulo progressivo de informações e a modos mais eficientes de descrever e manipular os objetos em estudo, gerando assim cadeias integradas de produção, sua imitação afobada pela filosofia é desastrosa. O problema do sentido, da finalidade e do valor do conhecimento dos fenômenos, as perguntas sobre os porquês e os para quês das nossas iniciativas e criações, as indagações mais gerais sobre os rumos do processo civilizatório - todo esse repertório parece absurdo e inacessível em vista da fragmentação da pesquisa imposta pelo procedimento científico.

Para ficar num exemplo apenas, proliferam hoje em dia na iniciação à pesquisa projetos em que se busca, através da associação entre coleta empírica de dados e métodos estatísticos, a definição de tabelas para a aferição da felicidade universal. Se se faz a questão sobre os pressupostos e os parâmetros à luz dos quais os dados são interpretados, uma versão banal do que é a natureza humana, geralmente tributária de uma leitura biologista equivocada e dogmática, é invocada sem o menor escrúpulo. Ficam de fora o caráter histórico e perspectivo de todo valor e saber, que por si só exigem do investigador a mais desenvolvida sensibilidade, tanto para nuances quanto para a eventual integração de seu tema - se calhar, a própria natureza humana - em um quadro abrangente. Mas, desde que o cientificismo tenha sido adotado como medida, não existe escapatória. Com ênfases distintas, mas direção semelhante, Nietzsche se mostra muito insatisfeito com tal situação:

Em todos os círculos acadêmicos, se tem o costume de cochichar nos ouvidos algo desta canção, quer dizer, este fato em todo lugar difundido: a utilização tão desejada em nossos dias do erudito a serviço de sua disciplina torna a cultura do erudito cada vez mais aleatória e inverossímil. Pois o campo de estudo das ciências é hoje tão extenso, que aquele que, com boas 
Pimenta, O.

disposições mas não excepcionais, quer aí produzir algo, se consagrará a uma especialidade muito particular e não terá qualquer preocupação com todas as outras. Se na sua especialidade ele está acima do vulgus, para tudo mais, quer dizer, para tudo que é importante, não se mostra diferente deste. Assim, um erudito, exclusivamente especializado, se parece com um operário de fábrica que, durante toda sua vida, não faz senão fabricar certo parafuso ou certo cabo para uma ferramenta ou uma máquina determinadas, tarefa na qual ele atinge, é preciso dizer, uma incrível virtuosidade. $\mathrm{Na}$ Alemanha, onde se pretende recobrir os fatos mais dolorosos com um glorioso manto de pensamento, se admira como sendo um fenômeno moral esta acanhada especialização de nossos eruditos e seu distanciamento cada vez maior da verdadeira cultura: a "fidelidade nas pequenas coisas", a "fidelidade do carroceiro", se torna um tema de ostentação, a falta de cultura fora dos limites da disciplina é apresentada como sinal de uma nobre sobriedade (BA/EE 1, KSA 1.648-650. Trad. N. C. de Melo Sobrinho).

Foi dito há pouco que um aspecto bastante delicado da atividade científica é a definição dos pressupostos e parâmetros em função dos quais se ajuíza sobre os dados empíricos da pesquisa. De maneira mais decisiva, talvez, o comentário é extensivo ao ponto principal da argumentação em andamento. Para que as observações de Nietzsche citadas acima sejam aproveitadas até o fim, cabe um recuo em direção ao seu horizonte global de inscrição, isto é, cabe explicitar certas posições que o filósofo defende a respeito da vida intelectual em geral. Por mais que ele insista em declarar seu apreço pelas ciências - aptas a educar para as virtudes epistêmicas quase como as matemáticas ensinam a Descartes o modelo e exercício de um método -, o tipo humano a elas dedicado não deve ser tomado como o mais alto na hierarquia espiritual da comunidade. Afinal,

Por mais gratos que sejamos ao espírito objetivo [...] deve-se, afinal, ter cautela também com a própria gratidão, e refrear o exagero com que ultimamente a renúncia e despersonalização do espírito é celebrada, como quase um fim em si, como redenção e transfiguração [...] $\mathrm{O}$ homem objetivo,

174 I Cad. Nietzsche, São Paulo, n. 33, p. 165-180, 2013. 
que já não amaldiçoa e xinga como o pessimista, o erudito ideal, no qual o instinto científico vem a florir por inteiro, após mil malogros totais e parciais, é seguramente um dos instrumentos mais preciosos que existem: mas isto nas mãos de alguém mais poderoso. [...] $\mathrm{O}$ homem objetivo é um instrumento, um precioso, facilmente vulnerável e embaçável instrumento de medição e jogo de espelhos, que devemos poupar e respeitar; mas ele não é uma meta, não é uma conclusão e elevação, um homem complementar em que se justifique a existência restante, um término - e menos ainda um começo, fecundação e causa primeira, nada de sólido, poderoso, firme em si mesmo, que aspire a dominar: antes um delicado, inflado, fino e flexível recipiente de formas, que deve esperar por uma substância e conteúdo qualquer, para então se "configurar" de acordo - geralmente um homem sem conteúdo e substância, "sem si”. (JGB/BM 207, KSA 5.134-137).

$\mathrm{O}$ que poderia ter gerado personagens como esses, e também a inclinação a considerá-los como tipos humanos exemplares? Certamente um ingrediente importante é o pertencimento a uma época estranha a exigências nobres em relação à formação individual, na qual "cada vez mais o trabalho tem a seu lado a boa consciência". Num tempo assim,

as pessoas já se envergonham do descanso; a reflexão demorada quase produz remorso. Pensam com o relógio na mão, enquanto almoçam, tendo os olhos voltados para os boletins da bolsa - vivem como alguém que a todo instante poderia 'perder algo'. [...] Pois viver continuamente à caça de ganhos obriga a despender o espírito até a exaustão, sempre fingindo, fraudando, antecipando-se aos outros: a autêntica virtude, agora, é fazer em menos tempo que os demais. [...] a inclinação à alegria já chama a si mesma 'necessidade de descanso' e começa a ter vergonha de si. 'Fazemos isso por nossa saúde' - é o que dizem as pessoas quando são flagradas numa excursão ao campo. Sim, logo poderíamos chegar ao ponto de não ceder ao pendor à vita contemplativa (ou seja, a passeios com pensamentos e amigos) sem autodesprezo e má consciência (FW/GC 329, KSA 3.233). 
Pimenta, O.

A frase de Nietzsche é mais do que eloquente, e as consequências do que ele descreveu são certas: liquidação, juntamente com a reflexão, de todo pendor pela cultura e pelo gosto elevados. A arte torna-se ornamento ou entretenimento, desligada de demandas realmente importantes para a vida da comunidade, e a filosofia, como foi dito, entra em competição com as ciências, em nítida desvantagem, dado seu baixo rendimento em termos de mercado. Mais um pouco e as metas para o devir coletivo passam a ser fixadas pelo planejamento de financistas, administradores, publicitários e vendedores de toda sorte. Não é de causar espanto que, a par do aumento da prosperidade material, decresçam proporcionalmente a complexidade e o alcance das produções da inteligência.

$\mathrm{O}$ bastidor mais recuado contra o qual se projeta a questão em estudo contrapõe o instinto de rebanho ao indivíduo de exceção. Embora não caiba dúvida de que a consolidação de tradições de pesquisa é necessária para a qualificação dos debates e para o refinamento das suas realizações "de ponta" - o que, de passagem, lembra as anotações de Thomas Kuhn a respeito da aquisição de um paradigma por uma comunidade científica -, pode bem ser que, em filosofia, as coisas não sejam assim tão simples. A especificidade de um pensamento filosófico autêntico mantém relações indissolúveis com a elaboração personalíssima das próprias vivências pelo pensador. Não é algo que aconteça toda hora, e menos ainda que possa ser produzido em série, graças a uma disciplina comum. De mais a mais, é sabido que qualquer ordem institucional tende a se perpetuar como que por inércia, afastando de si toda iniciativa à crítica de seus fundamentos. Desaparece assim a criação em nome da diferença, efeito daquele pathos da distância freqüentemente invocado por Nietzsche como sinal da coragem demandada pelo processo de investigação da verdade.

Desde o ponto de vista delineado, a circunstância em que nos encontramos traz consigo um impasse. No mínimo em vista das passagens citadas, o saldo aponta o conflito entre as atuais práticas de produção e divulgação filosóficas, amplamente admitidas, inclusive 
no campo dos estudos nietzschianos, e as considerações do próprio filósofo a respeito do assunto. Tudo indica que a tendência hegemônica hoje, favorável à abordagem erudita e especializada da obra de Nietzsche, embora dotada de valor propedêutico, acrescenta pouco àquilo que ele próprio entende serem as ações mais importantes da filosofia. Exercícios filosóficos regrados pelas convenções da erudição e pelo protocolo da especialização são proveitosos como uma espécie de higiene, protegendo contra o diletantismo e coisas afins, embora sejam insuficientes, por si sós, para fazer avançar o que realmente conta. Em que pese o elogio das virtudes epistêmicas - modéstia, retidão -, parece plausível que Nietzsche admita para elas um alcance preferencialmente instrumental. No melhor dos casos, são elemento preparatório para tarefas filosóficas superiores - dentre as quais se destacam, por todas as razões declinadas, o ensino e o cultivo da afirmação da existência.

Resta pensar que, enquanto tradição histórica, a filosofia quase sempre implicou o engajamento de seus iniciados na transformação de seu modo de viver - a lei da filosofia referida mais cedo. Deste ponto de vista, nos furtarmos ao compromisso de experimentar a liberdade de espírito lança alguma sombra sobre nossa lealdade em relação a Nietzsche. Será digno tratá-lo assim? E o que dizer quanto ao que oferecemos aos estudantes e colegas que andam em nossa companhia? Para enfrentar essas dúvidas, pode ser razoável que se medite sem pressa na cogitação nietzschiana abaixo, que desenvolve ao longo de linhas muito intensas, ainda que em nada convencionais ou academicamente dóceis, algumas práticas do espírito livre:

Habitantes, ou ao menos hóspedes, de muitos países de espírito; sempre escapando aos buracos úmidos e agradáveis a que nos pareciam confinar a predileção ou pré-aversão, a juventude, a origem, o acaso de homens e livros, ou mesmo a fadiga das andanças; cheios de malícia frente aos engodos da dependência, que se escondem em honras, dinheiro, cargos ou entusiasmos dos sentidos; até mesmo gratos às misérias e vicissitudes da doença, por que sempre nos livraram de alguma regra e seu 'preconceito', 
Pimenta, O.

gratos a Deus, Diabo, ovelha e verme que haja em nós, curiosos ao ponto do vício, investigadores a ponto de ser cruéis, com dedos impetuosos para o intangível, com dentes e estômagos para o mais indigesto, prontos para todo ofício que exija perspicácia e sentidos agudos, prontos para todo o risco, graças a um excesso de 'livre arbítrio', com almas de frente e de fundo, das quais não se vêem facilmente os últimos propósitos, com fachadas e bastidores que ninguém percorreria até o fim, escondidos sob o manto da luz, conquistadores, mesmo que pareçamos herdeiros e esbanjadores, colecionadores e arrumadores da manhã até a noite, avarentos de nossa riqueza e nossas gavetas abarrotadas, parcimoniosos no aprender e esquecer, inventivos em esquemas, às vezes orgulhosos de tábuas de categorias, às vezes pedantes, às vezes corujas do trabalho mesmo em pleno dia; quando necessário, até mesmo espantalhos - e atualmente isso é necessário: na medida em que somos os amigos natos, jurados e ciumentos da solidão, de nossa mais profunda, mais solar e mais noturna solidão—tal espécie de homens somos nós, nós, espíritos livres! E também vocês seriam algo assim, vocês que surgem? Vocês, novos filósofos? (JGB/BM 44, KSA 5.60-3).

\begin{abstract}
Considering statements made by Nietzsche in the distinct phases of his work, we intend to discuss if our current practises in teaching and researching, orienteded towards specialization and eruditeness, favour or not the breeding of free spirits, not without, preliminarly, link this notion to the general course of a philosophy commited to life's affirmation. Keywords: eruditeness - specialization - free spirits - life's affirmation.
\end{abstract}

\title{
referências bibliográficas
}

1. NIETZSCHE, F. Sämtliche Werke. Kritische Studienausgabe. Berlin/New York: de Gruyter, 1988, 15v.

2. _ . O nascimento da tragédia. Trad. J. Guinsburg. São Paulo: Cia da Letras, 1996.

178 I Cad. Nietzsche, São Paulo, n. 33, p. 165-180, 2013. 
3. . Segunda Consideração Intempestiva. Trad. Marco Antônio Casanova. Rio de Janeiro: Relume Dumará, 2003.

4. . Humano, demasiado humano I. Trad. Paulo César Souza. São Paulo: Cia das Letras, 2000.

5.__ A gaia ciência. Trad. Paulo César Souza. São Paulo: Cia das Letras, 2001.

6. _ Além do bem e do mal. Trad. Paulo César Souza. São Paulo: Cia das Letras, 1996.

Artigo recebido para publicação em 10/09/2012.

Artigo aceito para publicação em 20/10/2012. 
